\title{
HUBUNGAN ANTARA HARAPAN LAYANAN PEMBELAJARAN DENGAN TINGKAT KEPUASAN MAHASISWA (Studi kasus Program Magister Pendidikan Dasar UT)
}

\author{
Suroyo \\ Universitas Terbuka \\ e-mail: suroyo@ecampus.ut.ac.id
}

\begin{abstract}
The master program of Basic Education at Open University (UT) begins to admit students in 2015. In one year period the number of students has increased significantly to 497 students, located at 12 UT Regional Offices. The purpose of this correlational study is to analyze the relationship between students learning service expectations offered in 2 semesters with the level of student satisfaction regarding the aspects of administrative and academic services. The respondent is 73 students from 8 Regional Offices. The result showed that $59.1 \%$ of the respondents perceive general service as very important, and only $47,2 \%$ satisfied with the general service. There is a positive and significant correlation between expectation or perception of importance of general service and satisfaction $(r=0,559$ **; Sig $=0,00)$. Data on specific aspects of service, such as tutorial, assessment, et cetera, is provided. Students also indicates some hindrances, such as: difficulties in accessing the internet for online tutorials in remote ateas, friendliness and speed of information provided by UT staff, tutor's response discussions and late access opening,
\end{abstract}

Keywords: administrative and academic service, student's expectation and satisfaction, teaching materials.

\begin{abstract}
ABSTRAK
Magister Pendidikan Dasar (MPDr) Universitas Terbuka (UT) mulai menerima mahasiswa pada masa registrasi 2015.1 dan data pada 2016.1. Pada tahun 2017 jumlah mahasiswa registrasi 497 orang tersebar di 12 UPBJJ-UT. Tujuan penelitian ini adalah untuk mengukur hubungan antara harapan terhadap layanan pembelajaran dan kepuasan mahasiswa. Sampel penelitian sejumlah 73 mahasiswa dari 8 UPBJJ. Yang diperoleh dari pengambilan langsung, email, dan tutorial online. Jenis penelitian ini bersifat korelasional untuk menganalisis hubungan antara harapan layanan pembelajaran yang ditawarkan pada semester 1 dan 2 dengan tingkat kepuasan mahasiswa dari aspek pelayanan administrasi dan akademik. Hasil penelitian menunjukan harapan pada aspek layanan umum 59,1\% sangat penting sekali dan tingkat kepuasan $47,2 \%$ dalam kategori puas. Terdapat korelasi yang signifikan antara harapan dan kepuasan mahasiswa dalam aspek layanan akademik secara umum. Data tentang berbagai aspek spesifik layanan akademik juga dibahas Berbagai kendala yang dikemukakan mahasiswa mencaklup di anataranya: kesulitan akses jaringan internet utnuk tutorial online di daerah, keramahan dan kecepatan layanan layanan informasi dari staf UT, respon tutor terhadap diskusi tuton dan keterlamabtan pembukaan akses tuton, font bahan ajar yang dinilai terlalu kecil untuk siswa dewasa, kualitas soal ujian, dsb.
\end{abstract}


Kata kunci: bahan ajar, harapan dan kepuasan mahasiswa, pelayanan administrasi dan akademik.

Program Magister Pendidikan Dasar (MPDr) pada Pascasarjana Universitas Terbuka mulai menyelenggarakan pendidikan pada tahun 2015 dengan jumlah 273 mahasiswa. Dan dalam dua tahun jumlah mahasiswa teregistrasi mengalami peningkatan yang substansial menjadi 776 mahasiswa (Data PPs-UT 2016). Dalam berbagai studi tentang pendidikan jarak jauh dijelaskan bahwa peningkatan peserta didik dan kecenderungan mahasiswa untuk bertahan pada program sangat dipengaruhi oleh pengalaman belajar dan persepsi mahasiswa tentang kualitas layanan perguruan tinggi. Pada tahun 2016 Program Magister MPDr belum menghasilkan lulusan karena mahasiswa memerlukan minimal 4 semester. Program MPDr perlu memperoleh informasi dari mahasiswa maupun pengguna lainnya seperti tutor dan pakar bidang studi tentang kualitas layanan administrasi dan akademik yang disediakan oleh Universitas Terbuka. Sementara proses kegiatan belajar mandiri mahasiswa masih berlangsung, layanan pembelajaran memerlukan evaluasi formatif sebagai masukan untuk perbaikan dan penyempurnaan layanan administrasi dan akademik serta kualitas bahan ajar maupun revisi bahan ajar cetak setelah berusia 5 tahun. Kegiatan ini memerlukan masukan dari pengguna antara lain, pakar bidang ilmu, tutor dan mahasiswa.

Bahan ajar dalam pendidikan tinggi terbuka dan jarak jauh menggunakan berbagai macam media pembelajaran, meliputi bahan ajar cetak (BAC) pokok dan bahan ajar noncetak (BANC) (Knight \& Nestor, 2000). Kualitas bahan ajar cetak dalam pendidikan jarak jauh terutama dicirikan dari karakteristiknya untuk mempermudah mahasiswa memahami dan menguasai materi dalam ranah kognitif, afektif dan psikomotor melalui belajar mandiri. Analisis kualitas bahan ajar juga didasarkan pada aspek cakupan isi materi, penyajian materi, keterbebasan dari unsur SARAG (suku, agama, ras dan gender), dan penyajian substansi sebagai bahan ajar yang bersifat selfinstructional, yang dapat dipelajari sendiri dengan bantuan minimal dari orang lain.

Kepuasan dipandang sebagai kegembiraan atau kebahagiaan yang dirasakan seseorang ketika keinginan, persepsi atau harapan telah terpenuhi. Dalam konteks institusi pendidikan tinggi, kepuasan mahasiswa sebagai klien utamaperlu mendapat perhatian. Kepuasan mahasiswa merupakan respon emosional yang dihasilkan dari proses kognitif mengevaluasi perbandingan antara layanan yang diterima dengan harapan, kebutuhan atau persepsi (Lasley, 2001:220). Tanpa mahasiswa tidak ada program pendidikan yang dapat berlangsung. Keberlangsungan program dipengaruhi oleh upaya program studi untuk melayani mahasiswa melalui proses administrasi dan akademik yang berkualitas, sehingga mahasiswa sukses belajar dan lulus tepat waktu sesuai dengan harapan mahasiswa. Kepuasan mahasiswa menjadi strategi penting yang erat kaitannya dengan kesetiaan mahasiswa untuk persisten belajar di suatu lembaga pendidikan tinggi (Kunanusorn \& Puttawong, 2015). Dengan demikian perlu diupayakan agar kesenjangan antara harapan dan kepuasan mahasiswa diperkecil, bahkan dihilangkan, sebagai tolok ukur keberhasilan layanan administrasi akademik dalam pendidikan jarak jauh.

Bagian pelayanan pengadaan bahan ajar dan administrasi akademik mahasiswa mempunyai peran yang besar untuk meningkatkan kepuasan secara keseluruhan, dengan bersikap penuh empati dan itikat membantu kepada mahasiswa (Nell \& Cant, 2014). Kepuasan mahasiswa pada pendidikan tinggi terbuka dan jarak jauh melalui penelitian oleh Martz dan Shepherd (2007) menunjukkan bahwa umpan balik tepat waktu dan personal dari dosen akan meningkatkan kepuasan mahasiswa. Berdasarkan penelitian ini disarankan agar administrator pendidikan jarak 
jauh bekerja sama dengan dosen dan mencari cara dan upaya untuk meningkatkan kualitas bahan ajar, karena hal ini berhubungan dengan tutor dan mahasiswa. Staf akademik fakultas juga perlu menggunakan teknologi untuk meningkatakan 'kehadiran' (personal presence) di kelas virtual. Untuk menjaga mahasiswa tetap terlibat dalam kelas online dosen menggunakan forum diskusi elektronik, dan merespon email mahasiswa paling lama dalam 24 sampai 48 jam.

Penelitian yang dilakukan oleh Kunanusorn \& Puttawong (2015), menunjukkan bahwa terdapat hubungan antara persepsi mahasiswa dengan kesetiaan melalui kepuasan mahasiswa. Oleh sebab itu perlu perbaikan pada layanan administrasi dan akademik pada lembaga pendidikan tinggi untuk menciptakan kepuasan di antara mahasiswa. Penelitian lain dilakukan oleh Knight dan Nestor (2000) serta Nell dan Cant (2014) menyimpulkan bahwa bagian administrasi akademik mahasiswa perlu memfokuskan perhatian pada peningkatan empati kepada mahasiswa dalam upaya meningkatkan kepuasan secara menyeluruh, dan menyarankan agar pelayanan administrasi akademik bekerja secara independen, akurat dan tepat waktu. Hal ini paling penting berhubungan dengan pelayanan mahasiswa. Penelitian oleh Martz dan Shepherd (2007) berkaitan dengan pengelolaan pendidikan jarak jauh menyimpulkan berdasarkan analisis faktor mengeksplorasi 5 dasar konstruk berhubungan dengan kepuasan, yaitu: interaksi dosen, keadilan, isi materi mata kuliah, interaksi di kelas, dan penggunaan dan nilai teknologi.

Tujuan penelitian ini ada dua, pertama untuk menganalisis hubungan (korelasi) antara harapan mahasiswa terhadap layanan pembelajaran dengan tingkat kepuasan mahasiswa program magister MPDr UT. Dalam studi ini layanan pembelajaran mencakup pelayanan akademik dan administrasi. Ke dua, untuk mendeskripsikan penilaian mahasiswa terhadap kualitas bahan ajar, yang merupakan komponen sangat penting dalam proses akademik. Kualitas bahan ajar diukur dari berbagai indkator, seperti kesesuaian substansi modul dengan tujuan kurikulum, penyajian substansi dalam modul, tingkat keterbacaan modul, dsb.

Manfaat kajian ini bagi program studi adalah Magister Pendidikan Dasar adalah memproleh masukan tentang kualitas pelayanan administrasi akademik dan administrasi dan bahan ajar, sebagai dasar mencari alternative perbaikan.

\section{METODE PENELITIAN}

Penelitian ini merupakan penelitian deskriptif kuantitatif. Populasi penelitian ini adalah mahasiswa program Pascasarjana UT sebanyak 497 orang yang tersebar di 12 wilayah Indonesia, yaitu Bandung, Bogor, Batam, Jember, Malang, Medan, Padang, Palembang, Semarang, Serang, Surabaya, dan Sorong. Sampel penelitian sebanyak 73 mahasiswa yang dipilih secara stratified random sampling. Adapun Buku materi Pokok yang digunakan sebagai sampel sebanyak 8 judul.

Penelitian tentang kepuasan mahasiswa dan alumni dilakukan menggunakan angket via email dan wawancara kepada mahasiswa. Instrumen penelitian untuk analisis bahan ajar menggunakan kuesioner dan wawancara kepada mahasiswa dan tutor untuk 8 mata kuliah. Indikator yang digunakan dalam penelitian ini adalah: 1) layanan umum, 2) layanan registrasi, 3) layanan Tutorial Tatap Muka (TTM) dan Tutorial Online (Tuton), 4) bahan ajar, dan 5) layanan penyelenggaraan ujian. Sedangkan Untuk analisis bahan ajar indikator yang akan digunakan meliputi aspek: 1) Cakupan isi materi, 2) penyajian materi, 3) keterbebasan dari SARAG (suku, agama, ras dan gender), dan 4) kebahasaan penyampaian materi dalam kontek belajar mandiri.

Uji validitas instrumen berdasarkan hasil output nilai $r$ yang dihasilkan dari aplikasi Iteman 3.00 dilakukan dengan jumlah sampel responden 30 (tiga puluh). Butir pernyataan dalam instrumen kepuasan mahasiswa yang di bawah nilai $r_{\text {tabel }} 0,361(n=30 ; p=0,05)$ adalah butir 8 (kepuasan) 
0,268 tentang layanan pembayaran di bank mitra UT, butir 10 (kepuasan) 0,321 tentang penguasaan materi para tutor, butir 13 (kepuasan) 0,308 tentang kesesuaian pelaksanaan tutorial dengan jadwal, dan butir 32 (harapan/kepentingan) 0,321 tentang ketertiban pelaksanaan ujian. Uji reliabilitas instrumen dengan uji Alpha Cronbach menunjukan reliabititas tinggi sebesar 0,956.

\section{HASIL DAN PEMBAHASAN}

Profil responden terlihat pada Gambar 1. dan Gambar 2. berikut ini.

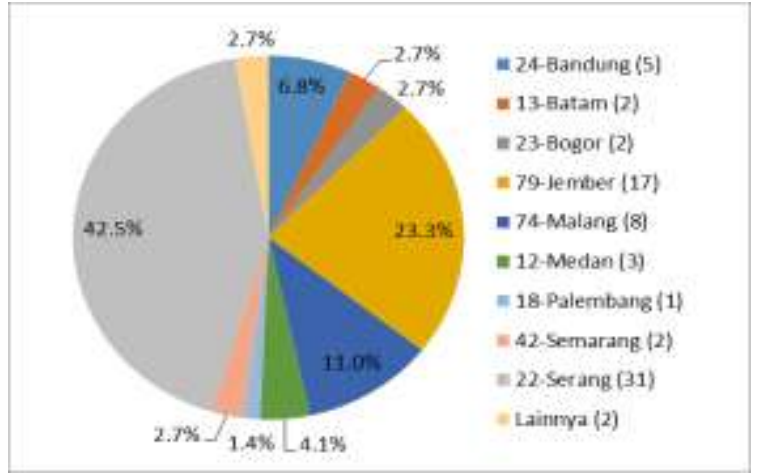

Gambar 1. Persentase responden/UPBJJ

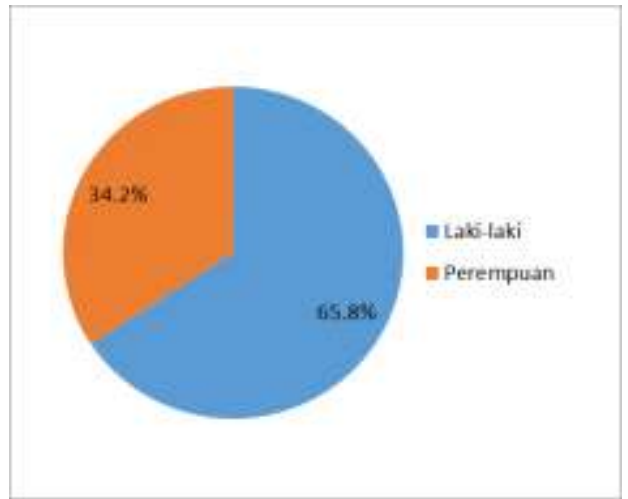

Gambar 2. Jenis kelamin

Berdasarkan Gambar 1 dan Gambar 2 responden terbesar berasal dari UPBJJ-UT Bogor $(42 \%)$ dan yang terkecil dari UPBJJ-UT Palembang $(1,4 \%)$. Jenis kelamin responden sebagian besar perempuan (65.5\%).

\section{Kepuasan dan Harapan/Kepentingan Mahasiswa S2 terhadap Layanan UT}

Kepuasan mahasiswa dalam aspek layanan terlihat seperti pada Gambar 3 sampai dengan Gambar 7.

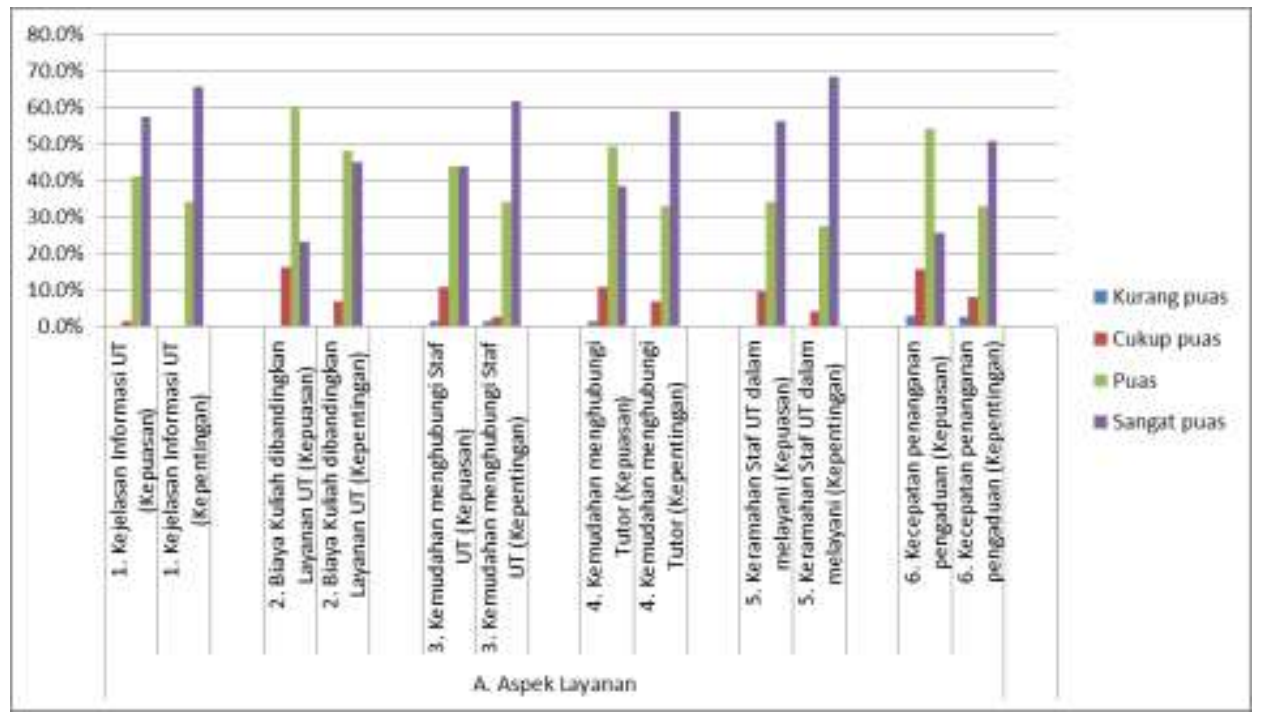

Gambar 3. Aspek layanan umum 
Gambar 3 menunjukkan bahwa dalam hal layanan umum, 45,7\% responden berharap penting dipenuhi, sedangkan tingkat kepuasan terhadap layanan umum antara 23\%-65,8\%. Pada aspek biaya kuliah, 45,2\% menyatakan penting sekali, dan kepuasan terhadap biaya sekolah hanya $23,3 \%$. Demikian pula pada kecepatan layanan pengaduan $50,7 \%$ menganggap sangat penting dan kepuasan mahasiswa yang diperoleh $15,7 \%$. menyatakan sangat puas. Korelasi antara harapan dengan kepuasan mahasiswa pada aspek layanan umum sebesar $r=0,559^{* *}$ dengan tingkat signifikansi sebesar 0,00. Dengan demikian korelasi pada aspek layanan umum antara kepuasan dan kepentingan layanan umum positif dan sangat signifikan.

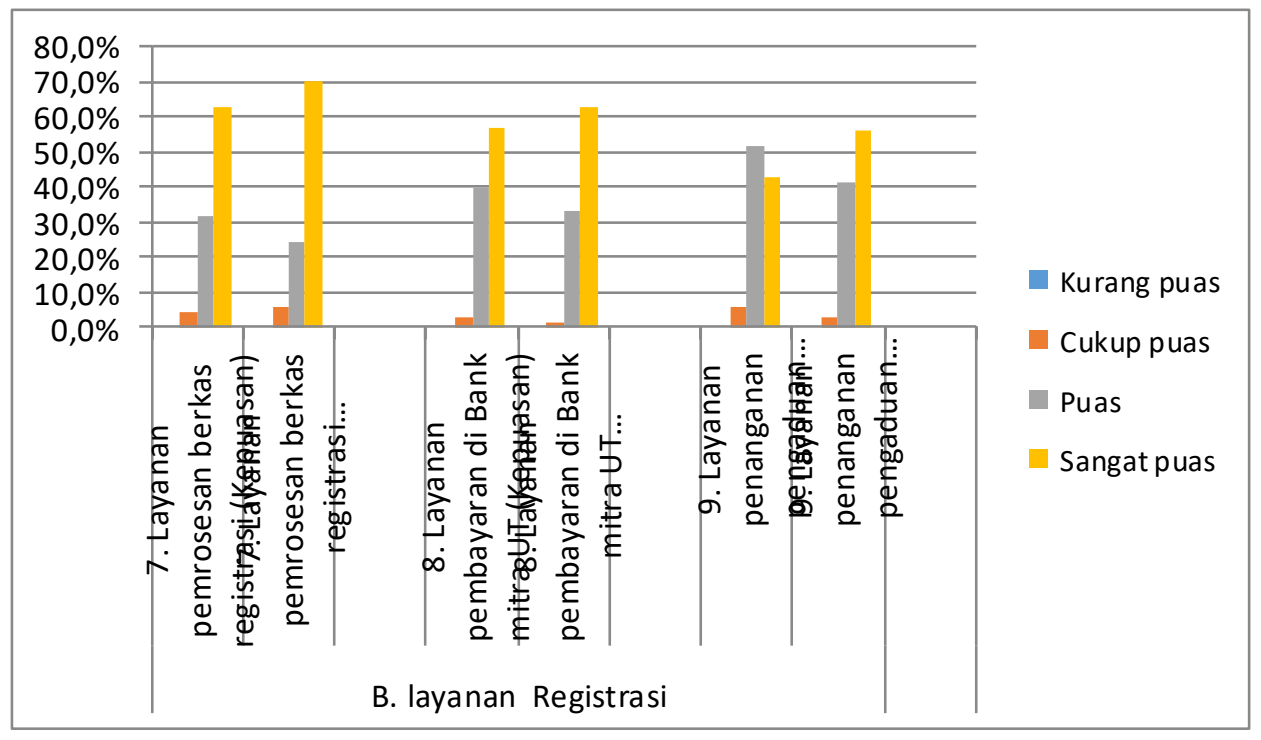

Gambar 4. Layanan registrasi

Sebagaimana pada Gambar 4, untuk layanan registrasi 56,2\%-69,9\% menyatakan sangat penting, dengan $43,1 \%-63 \%$ menyatakan sangat puas. Korelasi antara harapan dan kepuasan mahasiswa pada aspek layanan registrasi sebesar $r=0,138^{*}$ dengan tingkat signifikansi 0,042. Korelasi ini meskipun signifikan tetapi tidak terlalu kuat.

Pada Gambar 5, untuk layanan tutorial secara umum, 47,9\%-78,1\% menyatakan sangat penting, dan 35,6\%-68,5\% menyatakan puas. Tetapi dalam hal kemudahan akses ke tuton, 42,5\% menyatakan penting, dan kepuasan hanya 31,5\%. Korelasi antara harapan dan kepuasan mahasiswa pada aspek layanan tutorial sebesar $r=0,244^{* *}$ dengan tingkat signifikansi 0,00 . Dengan demikian dalam hal layanan tutorial, antara harapan dan kepuasan berkorelasi positif dan signifikan. 


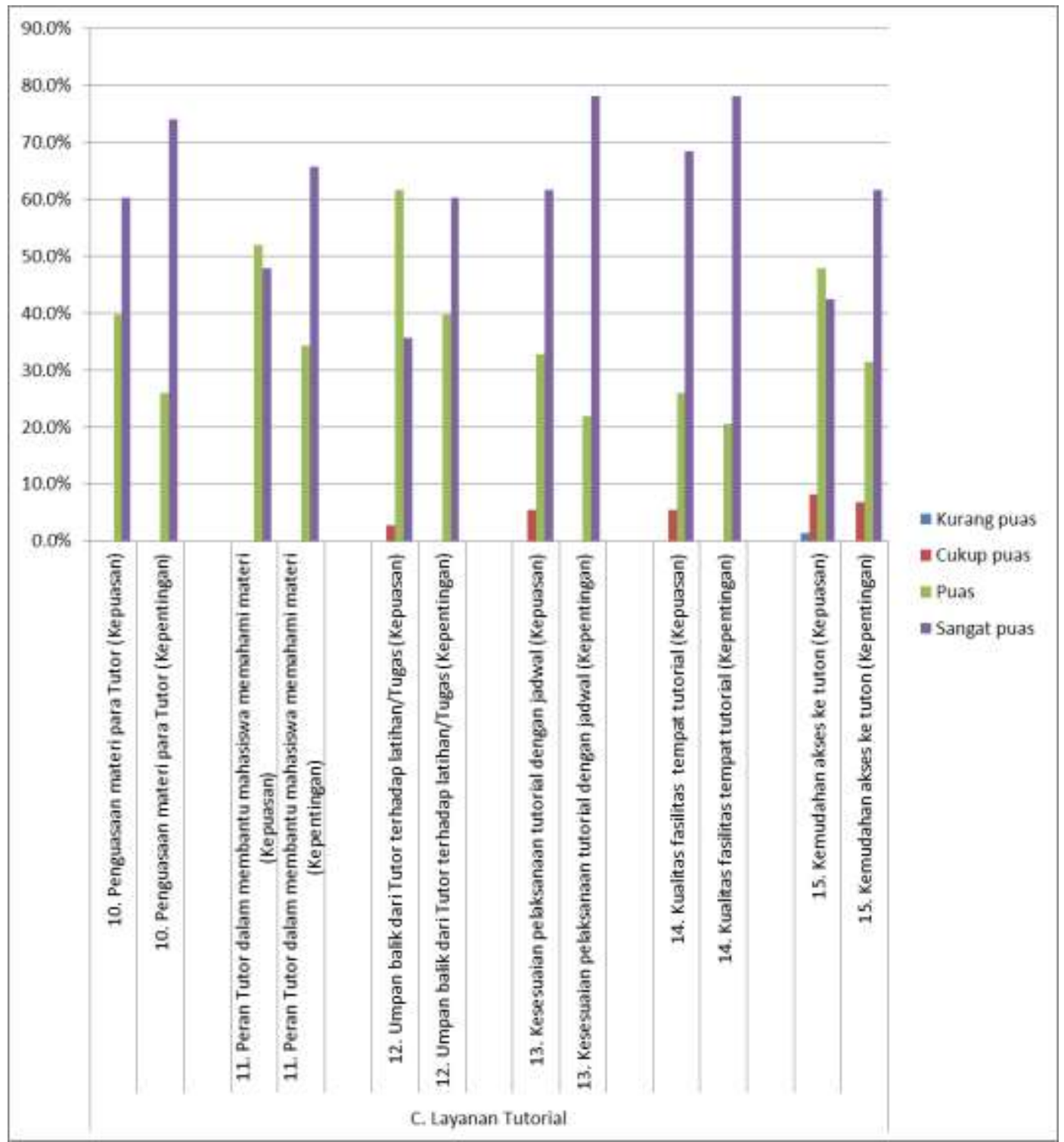

Gambar 5. Layanan tutorial

Gambar 6, menjelaskan harapan dan kepuasan mahasiswa tentang bahan ajar. Sebanyak $53,4 \%-74 \%$ menganggap bahan ajar sangat penting, dan kepuasan mencapai $23,3 \%-70,45 \%$. Korelasi antara harapan dan kepuasan mahasiswa pada aspek bahan ajar sebesar $r=0,321^{* *}$ dengan tingkat signifikansi 0,00 . Dengan demikian korelasi antara harapan dan kepuasan layanan bahan ajar signifikan tetapi tidak terlalu kuat. 


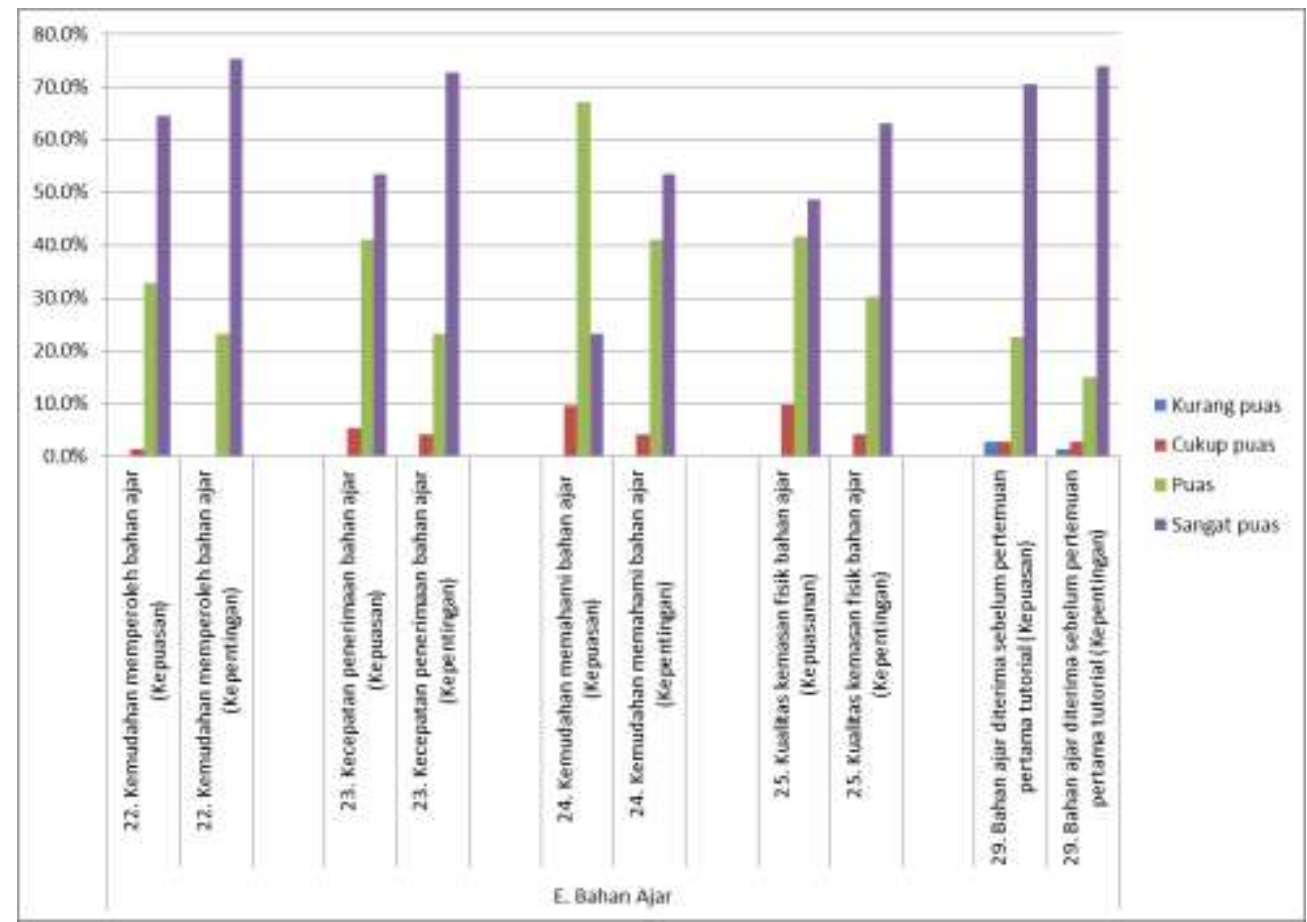

Gambar 6. Bahan ajar

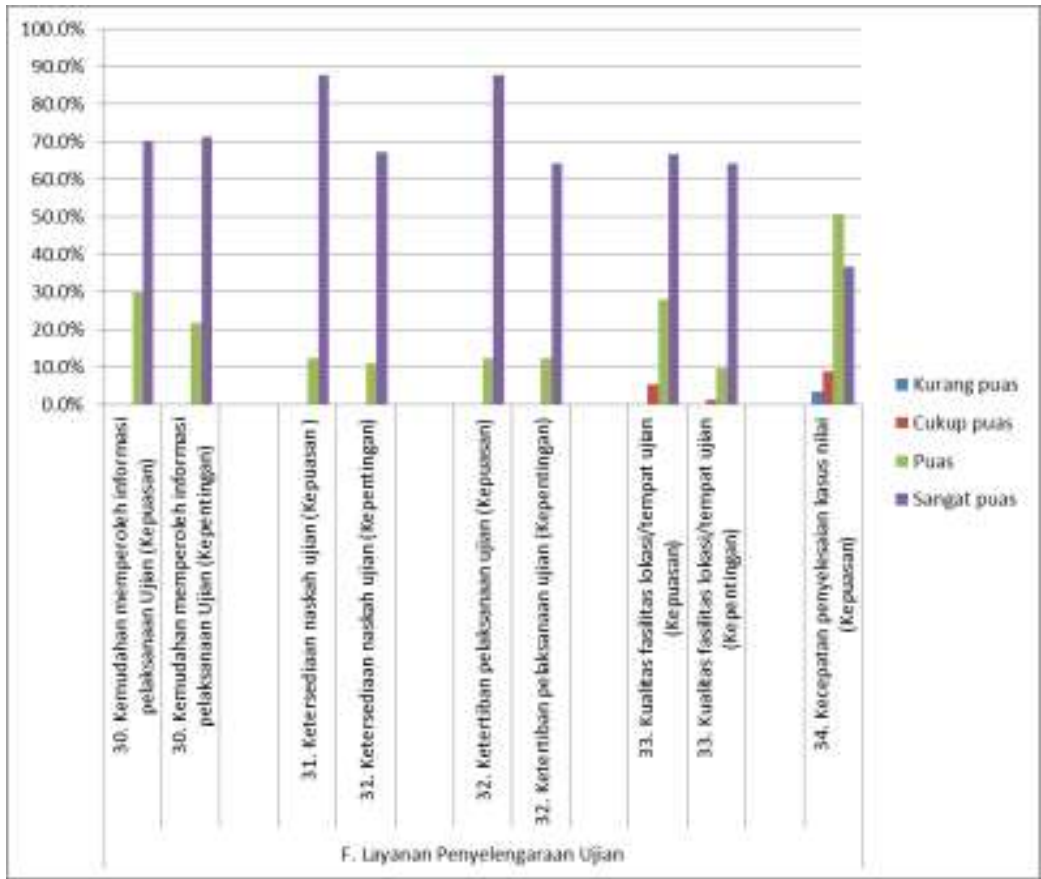

Gambar 7. Layanan penyelenggaraan ujian

Gambar 7 menunjukkan bahwa dalam hal layanan penyelenggaraan ujian, berkenaan dengan ketersediaan naskah dan ketertiban ujian, 64 \%-71,2\% menganggap penting, dan 
kepuasan $66.7 \%$ - 87,7\%. Penyelesaian kasus nilai $53,4 \%$ menganggap penting, dan kepuasan $36,8 \%$. Korelasi antara harapan dan kepuasan mahasiswa pada aspek layanan ujian sebesar $r=$ $0,121^{*}$ dengan tingkat signifikansi 0,00 . Dengan demikian korelasi antara harapan/persepsi kepentingan mahasiswa tentang layanan ujian dengan kepuasan signifikan tetapi tidak kuat. Rangkuman korelasi antara kepuasan dan kepentingan berdasarkan rata-rata disajikan pada Tabel 1.

Tabel 1. Rangkuman Mean, Standar Deviasi, Korelasi, dan Signifikansi antara Harapan dan Kepuasan Mahasiswa MPDr 2016.

\begin{tabular}{llccccc}
\hline \multicolumn{1}{c}{ Layanan } & \multicolumn{1}{c}{ SubAspek } & Rata-rata & SD & $\mid(a)$-(b)| & Korelasi & Sig (2 tailed) \\
\hline Umum UT & Harapan (a) & 3,5289 & 0,62340 & 0,245 & $0,559^{* *}$ & 0,00 \\
& Kepuasan (b) & 3,2834 & 0,68998 & & & \\
\multirow{2}{*}{ Registrasi } & Harapan (a) & 3,6037 & 0,55242 & 0,099 & $0,138^{*}$ & 0,042 \\
& Kepuasan (b) & 3,5047 & 0,57936 & & & \\
\hline \multirow{2}{*}{ Tutorial TTM } & Harapan (a) & 3,6759 & 0,49721 & 0,215 & $0,244^{* *}$ & 0,00 \\
& Kepuasan (b) & 3,4613 & 0,58484 & & & \\
\hline \multirow{2}{*}{ Tuton } & Harapan (a) & 3,5479 & 0,62452 & 0,233 & $0,403^{* *}$ & 0,00 \\
& Kepuasan (b) & 3,3151 & 0,68469 & & & 0,00 \\
\hline \multirow{2}{*}{ Bahan Ajar } & Harapan (a) & 3,6852 & 0,52204 & 0,183 & $0,321^{* *}$ & 0,00 \\
& Kepuasan (b) & 3,5023 & 0,60188 & & & \\
\hline \multirow{2}{*}{ Ujian } & Harapan (a) & 3,7877 & 0,44965 & 0,130 & $0,121^{*}$ & 0,00 \\
& Kepuasan (b) & 3,6576 & 0,56671 & & & \\
\hline
\end{tabular}

Berdasarkan Tabel 1. Secara keseluruhan rata-rata (mean) aspek kepuasan mahasiswa lebih kecil dibandingkan dengan aspek kepentingan mahasiswa dalam kisaran 0,099 sampai dengan 0,245. Perbedaan rata-rata antara kepuasan dan kepentingan dari terkecil sampai terbesar, yaitu dalam layanan: Registrasi $(0,099)$, ujian $(0,121)$. bahan ajar $(0,183)$, tutorial TTM $(0,244)$, Tuton $(0,233)$, dan layanan umum $(0,245)$. Korelasi antara kepuasan dan kepentingan secara keseluruhan berkorelasi positif dengan urutan terendah sampai tertinggi, yaitu aspek layanan:

a. Ujian $\left(0,121^{*}\right)$, berdasarkan komentar responden antara lain: Permohonan untuk evaluasi penilaian lebih diperjelas lagi dan lebih transparan. Sebagai contoh: pada mata kuliah Statistika Pendidikan, hampir semua mahasiswa mendapatkan nilai E (dari jumlah 17 mahasiswa S2 pendas 14 orang mendapatkan nilai E. Kita jadi masih menimbulkan pertanyaan kriteria penilaiannya.(Nilai Tugas+Tuton+Ujian).

b. Registrasi $\left(0,138^{*}\right)$, responden mengharapkan UT dapat bekerjasama selain dari yang sudah ada, terutama untuk pembayaran melalui e-banking.dengan lain yang mudah diakses di daerah antara lain seperti Bank BJB dan bank daerah.

c. Tutorial TTM $\left(0,244^{* *}\right)$, responden mengharapkan agar dalam pemilihan tutor perlu dimonitor dan evaluasi agar mampu menciptakan kesan "tutorial" bukan ceramah saja.

d. Bahan ajar $\left(0,321^{* *}\right)$, responden mengharapkan agar huruf (font) terlalu kecik diperbesar dan kertas sebaiknya HVS.

e. Tuton $\left(0,403^{* *}\right)$, responden mengharapkan tutor memberikan umpan balik kepada mahasiswa dan batasan waktu pengiriman tugas sampai UAS tugas jangan dulu ditutup sebelum UAS berlangsung. Nilai tugas tuton yang belum keluar agar diperiksa kembali, karena kemungkinan tugas sudah dikirim dan masih terdapat dalam data tutorial online.

f. Umum UT $\left(0,559^{* *}\right)$, responden sebagian besar menyatakan puas, namun mengharapkan untuk perlu ditingkatkan lagi keramahan staf UT dalam berkomunikasi secara jarak jauh agar 
mahasiswa merasa lebih nyaman.

Berdasarkan komparasi antara harapan dan kepuasan mahasiswa terhadap kualitas bahan ajar sebagai sarana pembelajaran yang pokok dalam sistem pendidikan jarak jauh berada pada posisi ditengah-tengah aspek layanan yang lain. Dengan demikian evaluasi bahan ajar menuntut agar program studi terus melakukan revisi secara berkala dalam upaya penyempurnaan dari segi keterbacaan, penyampaian materi, kelengkapan contoh dan latihan dan kemutakhiran.

\section{Penilaian Bahan Ajar Cetak oleh Pengguna}

Analisis kualitas bahan ajar MPDr dilakukan berdasarkan pendapat mahasiswa dan tutor untuk mata kuliah MPDR5101 Filsafat Pendidikan Dasar, MPDR5102 Integrasi Teori dan Praktek Pembelajaran, MPDR5105 Kebijakan dan Pengembangan Kurikulum Pendidikan Dasar, dan MPDR5201 Perencanaan, dan Pembiayaan Pendidikan Dasar. Sebagai sampel analisis adalah MPDR5102 Integrasi Teori dan Praktek Pembelajaran berdasarkan informasi proses pengembangan mengalami berbagai kendala.

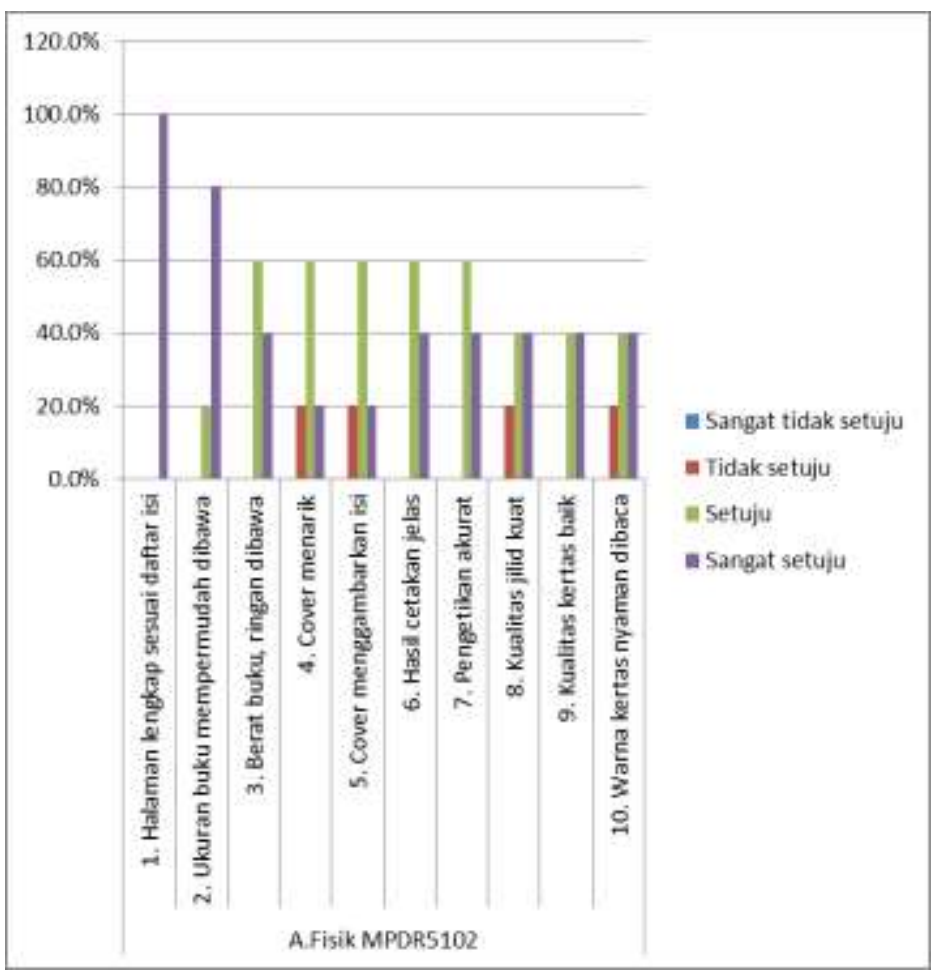

Gambar 8. Kualitas fisik BAC MPDR5102

Berdasarkan Gambar 8 seluruh responden menyatakan bahwa BAC secara fisik halamannya lengkap (100\%) dan ukuran buku membuat modul mudah dibawa (80\%) dan $80 \%$ menyatakan cover menarik. Tetapi hanya $20 \%$ yang menyatakan bahwa cover menggambarkan isi, kualitas jilid kuat (20\%), dan warna kertas nyaman dibaca (20\%). Dengan demikian beberapa aspek yang memerlukan perhatian adalah dalam hal kualitas kertas, cover dan jilid bahan ajar. 


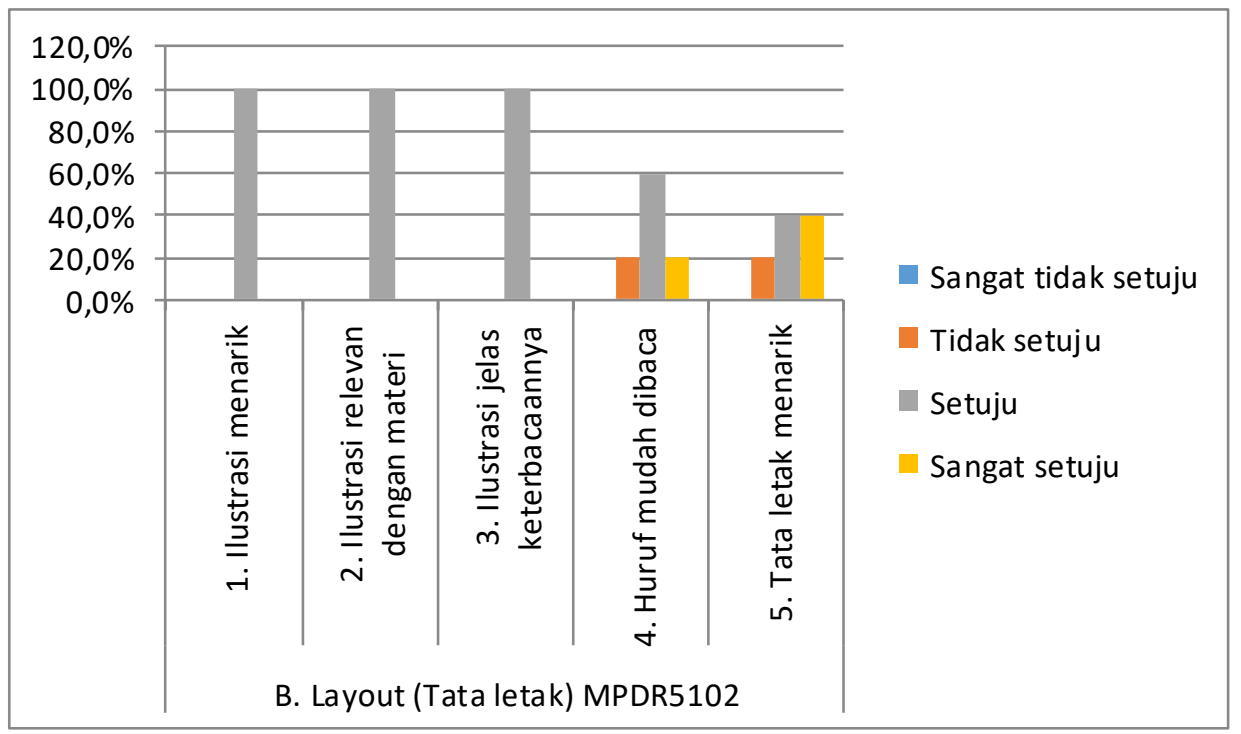

Gambar 9. Kualitas tata letak BAC MPDR5102

Gambar 9 menunjukkan kekuatan bahan ajar pada pernyataan ilustrasi menarik (100\%), ilustrasi relevan dengan materi (100\%), dan ilustrasi jelas keterbacaannya (100\%). Sedangkan keterbacaan huruf dan layout bahan ajar secara umum kurang menarik (80\%). Dengan demikian aspek ukuran huruf perlu diperbesar agar mudah dibaca.

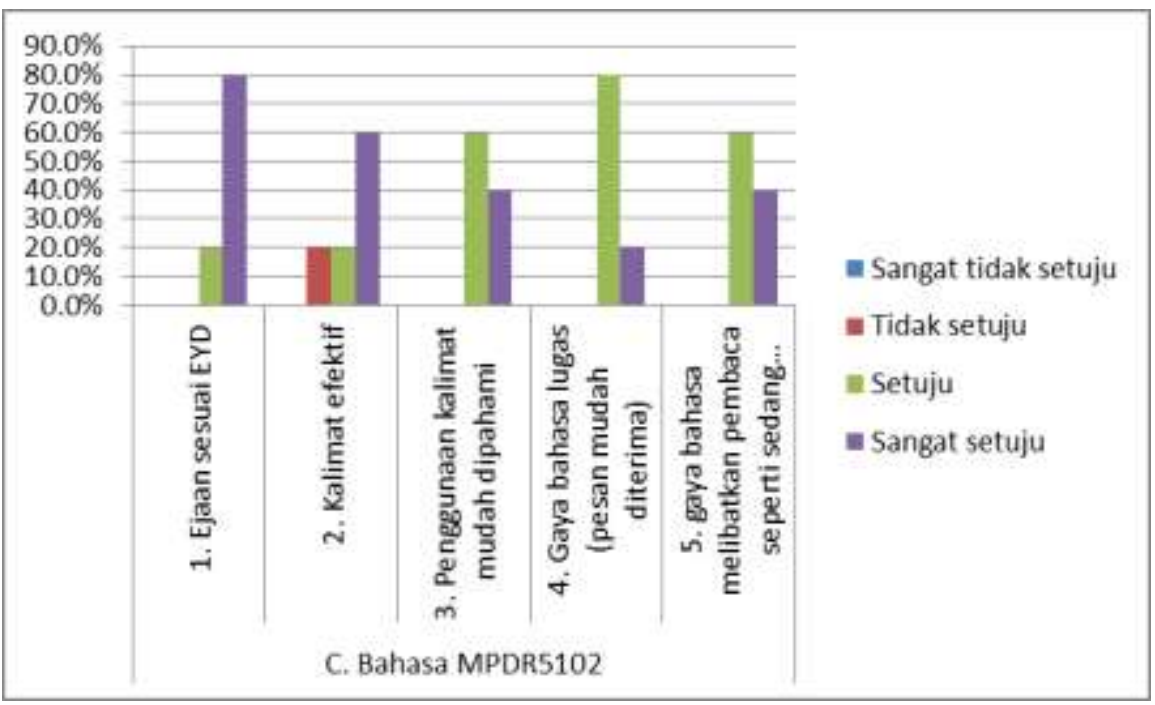

Gambar 10. Kualitas bahasa BAC MPDR5102

Gambar 10. menunjukkan 80 \% responden sangat setuju pada ejaan sesuai EYD, tetapi berpendapat bahwa kalimat-kalimat pada bahan ajar tidak efektif (80\%). Dengan demikian perlu lebih dicermati penggunaan kalimat yang efektif dalam penulisan materi bahan ajar, sehingga substansi buku materi pokok lebih mudah dipahami mahasiswa. 


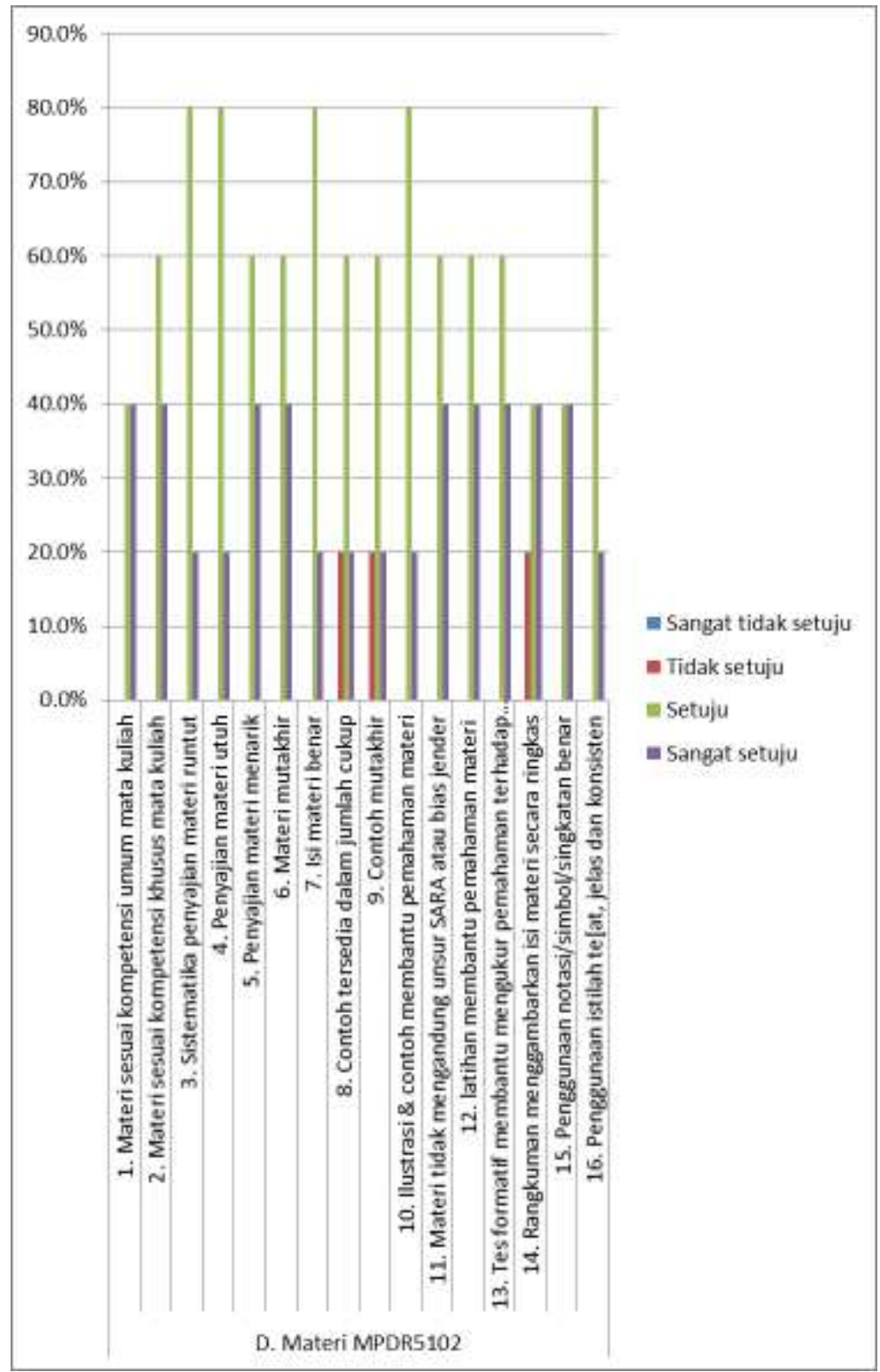

Gambar 11. Kualitas materi BAC MPDR5102

Gambar 11 menunjukkan $40 \%$ setuju bahwa materi atau substansi sesuai dengan kompetensi umum dan kompetensi khusus mata kuliah (40\%), penyajian materi menarik (40\%), materi tidak mengandung unsur SARAG, latihan membantu pemahaman materi dan tes formatif mengukur pemahaman materi (40\%), rangkuman menggambarkan isi materi $(40 \%)$, dan penggunaan notasi/symbol/singkatan benar. Namun responden menyatakan tidak setuju bahwa contoh tersedia dalam jumlah cukup (80\%), contoh tidak mutakhir (80\%), rangkuman tidak menggambarkan isi materi secara ringkas $(60 \%)$. Dengan demikian secara umum terdapat fisik buku, tataletak, penggunaan bahasa dan materi menunjukkan kualitas yang baik, namun perlu penyempurnaan pada kualitas jilid, warna kertas, ukuran huruf, contoh yang cukup dan mutakhir. 


\section{SIMPULAN}

Secara umum antara harapan dan kepuasan mahasiswa program magister MPDr UT pada layanan pembelajaran terdapat kesenjangan, terlihat dari harapan mahasiswa yang menganggap layanan pembelajaran sangat penting, dibandingkan dengan tingkat kepuasan mahasiswa. Cakupan isi materi bahan ajar MPDr sudah sesuai dengan tujuan kurikulum Program Magister Pendidikan Dasar, namun ada beberapa aspek yang belum dinilai baik, meliputi: kurangnya contoh dan kemutakhiran materi, dan bahwa rangkuman kurang menggambarkan materi sebagai sintesa. Penyajian materi bahan ajar cetak MPDr sebagai belajar mandiri sangat disetujui, tapi dianggap belum dapat memepermudah mahasiswa untuk mempelajarinya. Tingkat keterbacaan bahan ajar cetak MPDr dianggap penting, tetapi ukuran huruf yang dinyatakan terlalu kecil sukar dibaca. Keterbebasan, Substansi bahan ajar cetak MPDr dinilai bebas dari unsur SARAG (suku, agama, ras dan gender) (40\%). Untuk aspek penyampaian materi menggunakan bahasa untuk belajar mandiri (lebih informal) sebagian besar menyatakan (70\%), namun pengalimatan yang digunakan masih kurang efektif.

\section{ACKNOWLEDGMENTS}

Ucapan terima kasih disampaikan kepada Pimpinan Universitas Terbuka yang telah memberikan dana dan dukungan untuk penelitian ini.

\section{REFERENSI}

Knight, A. \& Nestor, M. (2000). A glossary of Australian vocational education and training terms. Kensington Park: National Center for Vocational Educational Research Ltd.

Kunanusorn, A. \& Puttawong, D. (2015). The mediating effect of satisfaction on student loyalty to higher education institution. European Scientific Journal, October 2015/SPECIAL/edition Vol.1.

Lashley, C. (2001). Empowerment: HR strategies for service excellence. Oxford: ButterworthHeinemann.

Martz, W. B. \& Shepherd, M. (2007). Managing distance education for success. International Journal of Web-Based Learning and Teaching Technologies, Volume 2, Issue 2.

Nell, C. E. \& Cant, M.C. (2014). Determining student perceptions regarding the most important service features and overall satisfaction with the service quality of a higher education institution.

Management, Vol. 19, 2014, pp. 63-87. 